\title{
Review
}

Algae 2020, 35(2): 107-121

https://doi.org/10.4490/algae.2020.35.5.15

Open Access

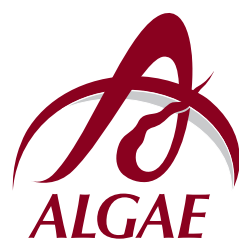

\section{Seaweed cultivation and utilization of Korea}

\author{
Eun Kyoung Hwang ${ }^{1}$ and Chan Sun Park ${ }^{2, *}$ \\ ${ }^{1}$ Aquatic Plant Variety Center, National Institute of Fisheries Science, Mokpo 58746, Korea \\ ${ }^{2}$ Department of Marine and Fisheries Resources, Mokpo National University, Muan 58554, Korea
}

Tribute to This paper is dedicated to the memory of Professor Chul Hyun Sohn (1943 2019)

Mariculture is regarded as the only option to supply the increasing demands for seaweeds as human food, feeds, fodder, and phycolloids in a sustainable manner. Technologies for culturing a range of seaweed species have been developed successively in Korea since the 1970s. In 2017, Korean marine farms produced 1,761,526 t of seaweed. The key focus of the industry is on the production of Pyropia (523,648 t), Undaria (622,613 t), and Saccharina (542,285 t). Pyropia is economically the most important species in Korea, accounting for up to $68 \%$ of total production value. As the top exporter of Pyropia in the world, Korea exported up to US \$525 million of Pyropia products to 110 countries in 2018. Other economically important genera include Sargassum, Ulva, Capsosiphon, Codium, and Gracilariopsis, all of which are used for food, and Gelidium, Pachymeniopsis, and Ecklonia which are used as raw material for phycocolloid extraction. Significant work has gone into developing more productive strains of key seaweed species, and in 2012 the Korean government began to certify seaweed varieties. To date, 19 seaweed cultivars have been registered including 13 Pyropia, 5 Undaria, and 1 Saccharina. The industry is now seeking not only to increase productivity but also to add value through processing. Convenience foods and snacks have been developed that target health-conscious consumers and utilize the nutritional properties of seaweeds. The industry is also seeking to promote the sustainability of seaweed farming. One seaweed company in Korea obtained the world's first ASC-MSC (Aquaculture Stewardship Council-Marine Stewardship Council) certification in 2019 and more are expected to follow their lead. With continued research support, the Korean seaweed industry plans to continue to expand to meet new market demands at a sustainable pace.

Key Words: breeding; cultivation; seaweeds; utilization

\section{INTRODUCTION}

Human societies face the enormous challenge of having to provide food and livelihoods to a population well over 9 billion people by the middle of the twenty-first century while addressing the disproportionate impacts of climate change and environmental degradation of the resource base (Food and Agriculture Organization of the United Nations 2018). Mariculture will play a vital role in sustainably meeting these increasing demands. Seaweed production will play a critical role in this development, providing not only food sources for humans but also animal fodder and chemical extracts. Furthermore, seaweed production is a carbon extractive activity, increasing its value as a sustainable development activity. Currently, world seaweed production is over 30 million tonnes fresh terms of the Creative Commons Attribution Non-Commercial License (http://creativecommons.org/licenses/by-nc/3.0/) which permits unrestricted non-commercial use, distribution, and reproduction in any medium, provided the original work is properly cited.
Received December 21, 2019, Accepted May 15, 2020

* Corresponding Author

E-mail: cspark85@mokpo.ac.kr

Tel: +82-61-450-2396, Fax: +82-61-452-8875 
weight (Food and Agriculture Organization of the United Nations 2017), and production continues to increase.

In 2017, Korea was the world's third-largest seaweed producer behind China and Indonesia, with an annual harvest of 1,761,526 t (Food and Agriculture Organization of the United Nations 2017). Korean seaweed production $(1,761,526 \mathrm{t})$ in 2017 consisted of 523,648 t of Pyropia, 622,613 t of Undaria and 542,285 t of Saccharina primarily harvest as food. Pyropia ('Gim' in Korean) is economically the most important species accounting for $71 \%$ of the total production value (Table 1) (Ministry of Oceans and Fisheries 2018). As the top exporter of Pyropia in the world, Korea exported US \$525 million of Pyropia products to 110 countries in 2018 (Table 2) (Korea Customs Service 2019).

Consumption of seaweed in Korea is changing qualitatively rather than quantitatively. It is diversifying from food-based products to functional health foods, beauty

Table 1. Production and value of farmed seaweed species in Korea in 2017

\begin{tabular}{lcc}
\hline \multicolumn{1}{c}{ Species } & $\begin{array}{c}\text { Production } \\
\text { (M/T, FW) }\end{array}$ & $\begin{array}{c}\text { Value } \\
(\mathbf{1 , 0 0 0} \text { US\$) }\end{array}$ \\
\hline Undaria pinnatifida & 622,613 & 101,076 \\
Saccharina japonica & 542,285 & 88,320 \\
Pyropia spp. & 523,648 & 617,507 \\
Sargassum fusiforme & 54,624 & 28,724 \\
Capsosiphon fulvescens & 6,276 & 19,340 \\
Ulva spp. & 6,159 & 6,188 \\
Codium fragile & 3,980 & 2,048 \\
Gracilariopsis spp. & 1,634 & 457 \\
Sargassum fulvellum & 301 & 695 \\
Other species & 6 & 4 \\
Total & $1,761,526$ & 864,409 \\
\hline
\end{tabular}

Data from Ministry of Oceans and Fisheries, Korea (2018), available from http://portal.fips.go.kr.

FW, fresh weight. products, and bio-therapeutics. Although over 30 species of seaweeds have traditionally been used as food by Koreans (Sohn 1998), the main species harvested are Sargassum, Ulva, Capsosiphon, Codium, and Gracilariopsis (Table 3). In addition to harvesting for food, harvesting of Gelidium, Pachymeniopsis, and Ecklonia occurs to provide the raw material for phycocolloid extraction and Sargassum and Ecklonia are used in the construction of artificial reef habitats. Research on seaweed cultivation techniques in Korea is focusing on maximizing natural productivity through selective breeding and reducing labor costs through automation.

In this review, we provide an overview of the history of Korean seaweed cultivation and introduce the cultivation technologies, breeding strategies, and processing used by industry. To help guide the future direction of the Korean seaweed cultivation industry, we also identify some of the necessary activities required to support the Korean industry in the future.

\section{SEAWEED CULTIVATION}

\section{History}

The history of cultivating seaweeds in Korea began with Pyropia. Records before 1425 indicate that Pyropia was being processed by chopping and drying (Bae 1991, Sohn 1998) and cultivation of Pyropia started between 1623 and 1649 (Chung 1937, Bae 1991, Sohn 1996). The first cultivation of Pyropia was undertaken around Taein Island, southwestern coast of Korea where a fisherman found some floating bamboo twigs with Pyropia attached to them and began to cultivate Pyropia by planting bamboo twigs along the seashore (Kang and Koh

Table 2. Seaweed export and import of Korea in 2018

\begin{tabular}{|c|c|c|c|c|c|}
\hline \multicolumn{3}{|c|}{ Export } & \multicolumn{3}{|c|}{ Import } \\
\hline Species & $\begin{array}{c}\text { Production } \\
\text { (M/T, FW) }\end{array}$ & $\begin{array}{c}\text { Value } \\
(1,000 \text { US } \$)\end{array}$ & Species & $\begin{array}{c}\text { Production } \\
(\mathrm{M} / \mathrm{T}, \mathrm{FW})\end{array}$ & $\begin{array}{c}\text { Value } \\
(1,000 \text { US } \$)\end{array}$ \\
\hline Pyropia & 22,097 & 525,527 & Cottoni \& Spinosum & 7,916 & 12,846 \\
\hline Undaria & 15,615 & 36,945 & Undaria & 4,417 & 6,408 \\
\hline Sargassum fusiforme & 1,665 & 20,848 & Gelidium & 1,157 & 5,940 \\
\hline Saccharina & 923 & 5,587 & Pyropia & 40 & 945 \\
\hline Gelidium & 292 & 3,379 & Sargassum fusiforme & 105 & 798 \\
\hline Ulva & 91 & 1,535 & Gigartina & 134 & 481 \\
\hline \multirow[t]{2}{*}{ Others } & 1,351 & 7,185 & Chondrus & 218 & 367 \\
\hline & & & Others & 355 & 377 \\
\hline Total & 42,033 & 601,006 & Total & 14,341 & 28,161 \\
\hline
\end{tabular}

Data from the Korea Customs Service (2019), available at http://www.customs.go.kr.

FW, fresh weight. 
1977). Use of the bamboo twig cultivation method continued until 1986 around Taein Island and its vicinity on the south coast, but this method is no longer used (Sohn 1998). Development of a horizontal net system for Pyropia cultivation in 1928 (Kang and Koh 1977) was refined and popularized through the use of synthetic nets in the 1960s (Yoo 1964). This facilitated the rapid expansion of seaweed farming in Korea in the 1970s. The initial rapid growth of the industry resulted in low-quality seaweed products, genetic degradation, poor adaptation to the environment, and increased incidence of disease. These challenges emphasized the needs for research to support the industry, and a particular emphasis was placed on breeding cultivars that performed well on farms and delivered high-quality products. Research on breeding Pyropia began in the 1980s (Hong et al. 1989, Shin et al. 1997, Kim 2001, Hwang et al. 2010, Park and Hwang 2014,
2015), and genetic analysis became available as a tool to support development in the early 2000s (Choi et al. 2000, 2013, Jin et al. 2000, Shin 2003, Hwang et al. 2005, Kim et al. 2011).

To maximize production, research on seaweed farming has not been limited to local species. Transplantation of Japanese varieties of S. japonica into Korea occurred in the 1960s (Chang and Geon 1970), and selective breeding to extend cultivation periods has recently been undertaken (Hwang et al. 2017). Newly introduced species into Korean seaweed cultivation include three green seaweeds, Codium (Hwang et al. 2008b), Capsosiphon (Sohn 1998, Hwang et al. 2003), and Ulva (Yoon et al. 2003, Park and Hwang 2011); five brown seaweeds, Ecklonia (Hwang et al. 2013), Eisenia, Costaria, Undariopsis (Hwang et al. 2011), and Sargassum (Sohn 1998, Hwang et al. 2007); and one red seaweed, Gracilariopsis (Sohn 2009).

Table 3. Seaweeds used as food in Korea

\begin{tabular}{|c|c|c|c|c|}
\hline Species name & Korean name & Preparation & Cooking method & Remark \\
\hline \multicolumn{5}{|l|}{ Chlorophyceae } \\
\hline Monostroma complex & Hotparae & f, $d$ & Various seasoning by soy sauce & M. grevillea, M. nitidum \\
\hline Ulva complex & Parae & f, d & Sesame oil, sometimes vinegar & $\begin{array}{l}\text { U. prolifera, U. com- } \\
\text { pressa, U. intestinalis, } \\
\text { E. linza, U. clathrata }\end{array}$ \\
\hline Capsosiphon fulvescens & Maesaengi & $\mathrm{f}$ & Boiled soup with oyster & - \\
\hline Codium fragile & Cheonggak & f, $d$ & $\begin{array}{l}\text { Seasoning by soy sauce and vinegar, } \\
\text { mix to kimchi }\end{array}$ & - \\
\hline \multicolumn{5}{|l|}{ Phaeophyceae } \\
\hline Scytosiphon lomentaria & Korimae & $\mathrm{f}$ & Various seasoning soup, fried in oil & - \\
\hline Ecklonia stolonifera & Kompi & f, $d$ & Fresh salad & - \\
\hline Undaria pinnatifida & Miyok & $f, d, s$ & $\begin{array}{l}\text { Fried in oil, boiled soup, soaked with } \\
\text { vinegar, soy sauce and sugar in water }\end{array}$ & - \\
\hline U. peterseniana & Nolmiyok & $f, d, s$ & $\begin{array}{l}\text { Fried in oil, boiled soup, soaked with } \\
\text { vinegar, soy sauce and sugar in water }\end{array}$ & - \\
\hline Saccharina japonica & Dasima & $f, d$ & Fried in oil, soup & - \\
\hline Pelvetia siliquosa & Thumbugi & f, $d$ & Steamed salad & - \\
\hline Sargassum fusiforme & Tot & f, $d$ & Various seasoning & - \\
\hline S. fulvellum & Mojaban & f, $d$ & Various seasoning & - \\
\hline S. horneri & Kwaengsaegi-mojaban & f, d & Various seasoning & - \\
\hline \multicolumn{5}{|l|}{ Rhodophyceae } \\
\hline Pyropia complex & Gim & f, $d$ & Toasted, seasoning, rolled with rice & $\begin{array}{l}\text { P. yessoensis, } \text { P. seriata, } \\
\text { P. dentata }\end{array}$ \\
\hline Nemalion vermiculare & Chamguksunamul & $\mathrm{f}$ & Salad & - \\
\hline Gelidium amansii & Umutkasari & d & Extracted agar & - \\
\hline Pterocladiella capillacea & Kaeumu & $\mathrm{d}$ & Extracted agar & - \\
\hline Gloiopeltis furcata & Bultunggasari & $f, d$ & Mixed soup, seasoning & - \\
\hline G. tenax & Pulgasari & f, $d$ & Mixed soup, seasoning & - \\
\hline G. complanata & Aekipulgasari & f, $d$ & Mixed soup, seasoning & - \\
\hline Grateloupia asiatica & Jinaejinuari & $f, d$ & Salad & - \\
\hline G. subpectinata & Bitsaldobak & $f, d$ & Salad & - \\
\hline Gracilariopsis chorda & Gaekkoshiraegi & $\mathrm{f}$ & Various seasoning & - \\
\hline Chondria crassicaulis & Gaeseoshil & f, d & Various seasoning & - \\
\hline
\end{tabular}

Modified from the Table 2 of Sohn (1998).

f, fresh; d, dried; s, salted. 


\section{Cultivation technology}

The largest concentration of seaweed culture grounds in Korea is located on the southwestern coast, where nearly $90 \%$ of total seaweed production occurs (Sohn 1996, 1998). The dominant aquaculture species include Pyropia spp., Undaria pinnatifida, and Saccharina japonica which collectively accounts for $96 \%$ of the total production (Table 1).

Pyropia. The main species in cultivation have change from Pyropia yezoensis, P. tenera, and P. kuniedae in the 1970 s to P. yezoensis, P. seriata, and P. dentata today (Kang 1972, Sohn 1996, 1998). Pyropia cultivation technology improved significantly in the 1960s (Sohn 1998) following the introduction of an artificial seeding method based on the culture of conchocelis in oyster shells. Further development in the early 1980s, saw the fixed-pole system replaced by a floating production system and an increase in the use of frozen seeded nets. The annual production of Pyropia has increased even more markedly since the 1980s due to the artificial seeding, introduction of new species, and expansion of the culture grounds.

The Pyropia cultivation process begins with settling the free-living conchocelis stage of the algae onto shells in March (Fig. 1A). Oyster shells are used as the substrate as these can be obtained cheaply and easily from oyster farmers. The conchocelis filaments grow densely within these shells (Fig. 1B). The seeded oyster shells are cultured by horizontal or vertical culture method. In the horizontal culture method, oyster shells with conchocelis filaments are laid and cultured on the floor of shallow concrete tanks or wooden boxes which are covered with polyethene film (Fig. 1C). This horizontal culture method is normally used for outdoor seeding. In the vertical culture method, oyster shells are tied into string in sets of 20 and dangled from rods and suspended in seawater tanks (Fig. 1D). This method can culture 3-4 times more shells than the horizontal method but has the disadvantage of uneven growth from top to bottom. From late September to early October, the conchocelis mature in the oyster shells and release conchospores. At this time, cultivation nets are placed in the culture tanks and become seeded with conchospores. During this period, the seawater temperature begins to drop below $22^{\circ} \mathrm{C}$. The temperature during this period is variable depending on where the cultivation grounds are located.

The seeding of Pyropia is undertaken using either the outdoor seeding or the indoor seeding method. For outdoor seeding, farmers hang vertical or horizontal bags of slender mosquito net containing crushed oyster shell, at regular intervals on the cultivation nets. The nets are placed in a large plastic envelope and moved to the sea for seeding (Fig. 1E). Although the outdoor seeding method can be conducted in any culture ground, this method is highly affected by weather and requires high labor inputs and time. The indoor seeding method uses a big wheel ( $>5 \mathrm{~m}$ in diameter) that rotates the cultivation nets through the spore tank. The bottom part of the wheel is immersed in seawater to allow the conchospores to attach on the net (Fig. 1F). This indoor seeding method ensures that only the desired cultivar is seeded onto the nets and allows conchospore density to be adjusted as needed. However, outdoor seeding method still more common in Korea because it does not require a large investment in infrastructure.

During the growing season, Pyropia nets supported on poles (Fig. 1G) or on a floating system (Fig. 1H \& I). With the floating system, it is necessary to periodically expose Pyropia nets to the air to improve growth and reduce epiphytes. Farmers use a tidal cycle to flip over the nets automatically; a unique method of Pyropia cultivation in Korea (Oohusa 1993, Sohn 1998).

Undaria and Saccharina. The Korean seaweed industry produced more than 622,613 tons of $U$. pinnatifida in 2017 (Table 1, Fig. 2A), accounting for 35\% of Korean seaweed production. The first artificial seeding of Undaria occurred in 1967 (Sohn 1998). The seeding method involves winding special seed string around a PVC frame (ca. $45 \times 55 \mathrm{~cm}$ ) (Fig. 2B). The frame is then used as a zoospore collector. These collectors are hung vertically in a concrete tank containing reproductive sporophyte blades. Seawater in the culture tank is changed once a month and does not have additional nutrients added. The tanks are exposed to ambient sunlight that is filtered through windows. The initial seawater temperature is approximately $17^{\circ} \mathrm{C}$, but if the temperature exceeds $25^{\circ} \mathrm{C}$ during the summer, window shades are used to lower the light level to about $10 \mu \mathrm{mol}$ photons $\mathrm{m}^{-2} \mathrm{~s}^{-1}$ (Sohn and Kain 1989, Sohn 1998). From September to October, when the seawater temperature falls below $23^{\circ} \mathrm{C}$, the seed frames are taken to intermediate culture grounds to allow the young sporophytes to adapt to open seawater conditions (Fig. 2C). Once the young fronds have grown to $0.5-1 \mathrm{~cm}$ in length, the seed strings are removed from the seed frame and attached to a culture rope in one of several ways. One popular method is to cut the string into ca. 3-4 cm lengths (Fig. 2D) and then insert these short strings through the lay of the culture rope (Fig. 2E) or a thinner intermediate rope at $30 \mathrm{~cm}$ intervals. If an intermediate rope is used, it is then attached to or wound 

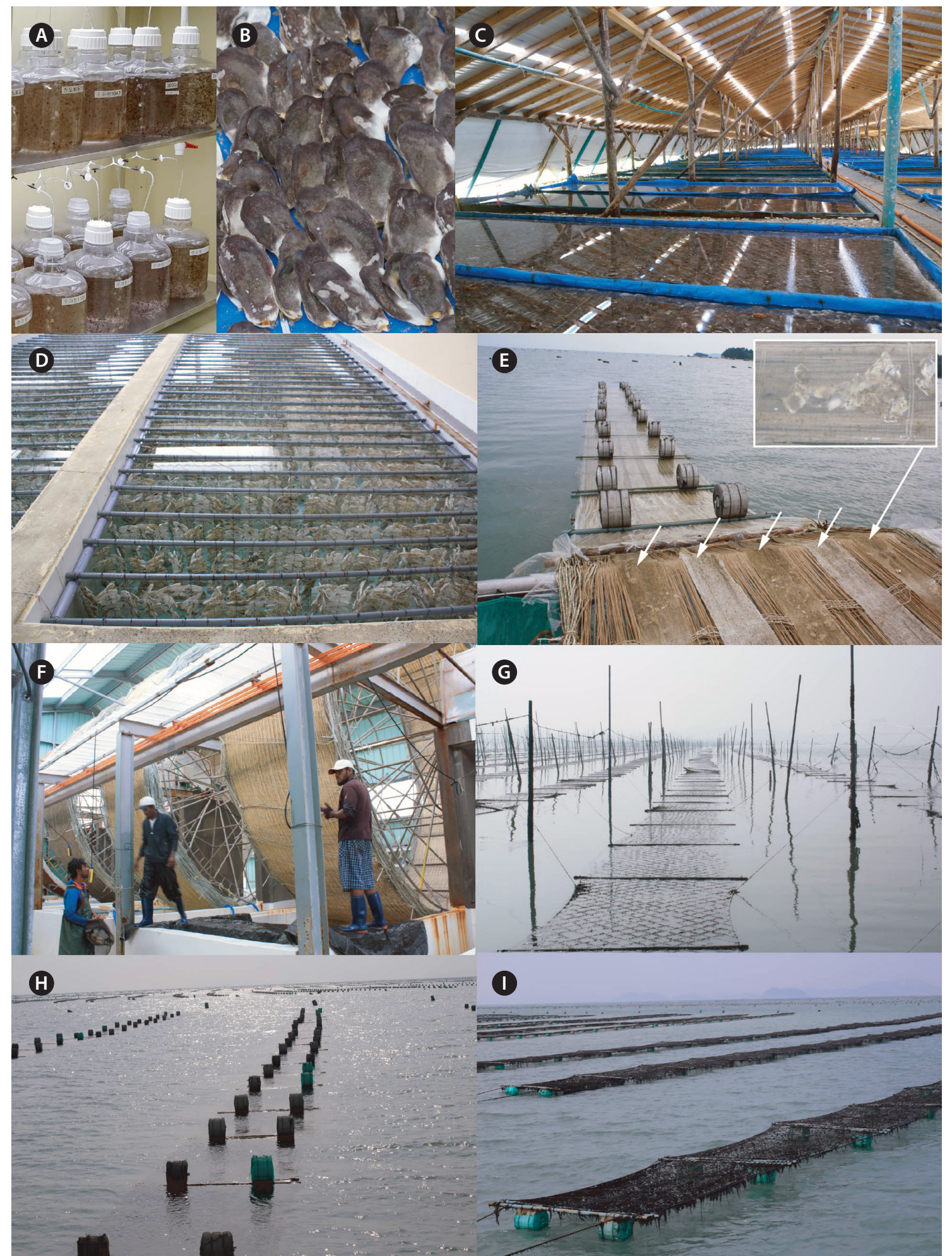

(1)

Fig. 1. Artificial seeding and cultivation of Pyropia in Korea. (A) Free-living conchocelis culture of Pyropia. (B) Pyropia conchocelis in oyster shells. (C) Oyster shell bearing conchocelis filaments culture in horizontal culture tank. (D) Oyster shell bearing conchocelis filaments culture in vertical concrete tank. (E) Outdoor seeding of Pyropia showing the slender mosquito net bags (arrows, included oyster shell pieces to facilitate the release of the inner conchospores) with seeding nets on sea surface. (F) Seeding wheel with cultivation nets, immersed seawater tank containing oyster shell bearing conchocelis filaments. (G) Fixing pole system of Pyropia. (H \& I) Floating system of Pyropia. Cultivation nets are submerged under sea surface $(\mathrm{H})$ and exposure to the air (I). 


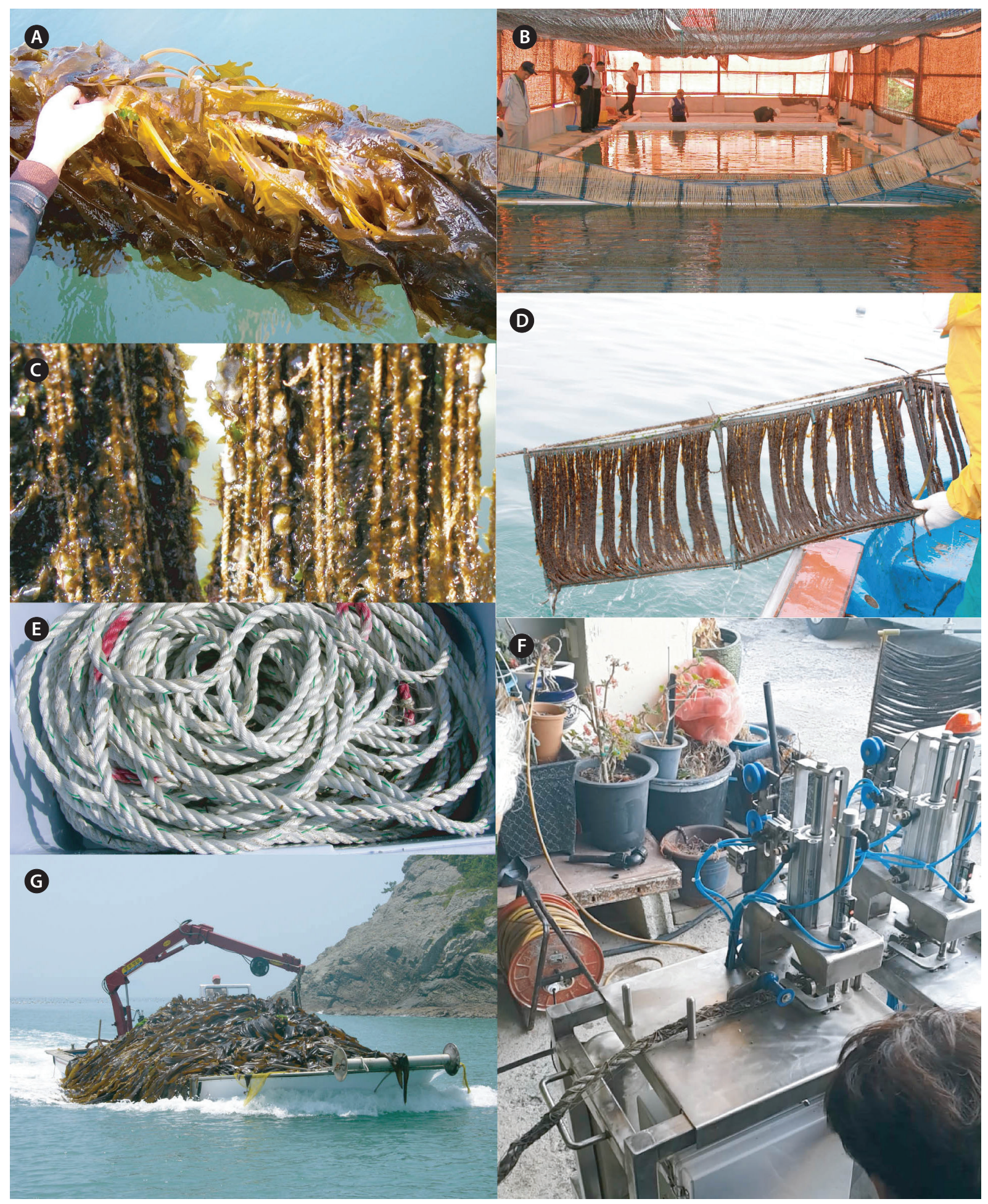

Fig. 2. Artificial seeding and cultivation of Undaria and Saccharina in Korea. (A) Cultivation ground of Undaria pinnatifida. (B) Tank culture of seedling of kelp. (C) Young sporophytes of kelp after nursery culture. (D) Nursery culture of kelp. (E) Cultivation rope inserted seed fibers. (F) Automatic sewing machine for insertion of seed fibers to cultivation rope. (G) Harvesting ship of Saccharina japonica. 
around the main culture rope. Recently, a sewing machine (Fig. 2F) for this process has been developed that inserts seed string pieces into the rope automatically, therefore reducing labor and increasing efficiency.

The first S. japonica (Fig. 2G) farm was established in Ulsan in 1968. Following the introduction of the mature thalli from Hokkaido, Japan in 1969, and commercial cultivation began in the Jumunjin region, Gangwon Province on the central eastern coast in 1971 (Sohn 1998). Following the successful transfer of plants from the east coast and the development of suitable culture technologies, the S. japonica culture grounds have expanded to the south coast. The seeding and cultivation method of S. japonica is similar to that used for $U$. pinnatifida. The seeding process for $S$. japonica commences in September, once the seed production of $U$. pinnatifida ends. The shared use of resources for seeding the two species allows the use of production facilities to be maximized.

S. japonica seeding begins when the seawater temperature begins to drop below $19^{\circ} \mathrm{C}$. The lower temperature allows for natural seawater to be used without the need for facilities to cool the water. After 1 month in the hatchery tanks and one month in nursery culture in the field, the main production period S. japonica commences. Production lines are seeded with seed fibers by insertion of fibers through the lines or winding of seed fibers around them. The choice of technique depends on whether the kelp will be used for human food or abalone feed. Edible kelp is grown into large and thick thalli by regularly thinning-out and harvesting to leave ten individuals per bundle. If the kelp is used for abalone feed, the lines are harvested all at once. Kelp seedling producers sell seedlings from November to March, and so abalone farmers can purchase kelp every month depending on the farms feed requirements.

Sargassum. Two Sargassum species are cultivated in Korea, S. fusiforme and S. fulvellum. Nearly $90 \%$ of S. fusiforme production is exported to Japan, and S. fulvellum is mainly used domestically for food or seedlings for marine forest restoration.

S. fusiforme has been cultured since 1984 around Wando, Jeonnam Province in the western region of the Korean south coast (Sohn 1998). However, cultivation of this species now also occurs in other regions in Jeonnam. The young fronds of S. fusiforme (5-10 cm in length) are collected from the natural beds, and about 3-4 young fronds are inserted into the seeding rope at a $5-10 \mathrm{~cm}$ interval. The seeding rope is then attached to the main cultivation rope using a second-hand fishing net (Fig. 3A). The cultivation period of $S$. fusiforme runs from November to
May. There is no biological and / or cultural significance to starting the cultivation in November. The only reason for doing so is to avoid the busiest period for Undaria cultivation. After transplanting the seed plants onto the main culture ropes, S. fusiforme flourishes and reaches full growth between May and June (Fig. 3B). Artificial seeding has described by Hwang et al. (1994a, 1994b, 1999) and is based on the reproduction patterns of this species. Recently culture methods have been used to regenerate seedlings from holdfasts by leaving the holdfast on the culture rope after harvesting in June. The holdfasts left on the culture rope are cut with a knife, leaving a layer 5-8 mm thick (Fig. 3C). The following year, young fronds grow densely from the holdfasts and can be thinned out and transplanted on to new culture ropes. Each "holdfast" rope produces enough seedings to stock 5-6 culture ropes.

S. fulvellum (Fig. 3D) has recently been introduced to the seaweed aquaculture industry in Korea. Artificial seeding and tank culture methods of this species followed the method described by Hwang et al. (2007). After the seeding of embryos of $S$. fulvellum, seedlings are reared in a culture tank for 60 days until they grow $5 \mathrm{~mm}$ in length. The young thalli of $S$. fulvellum can be significantly impacted by grazing during the period of nursery culture. However, plants that grow rapidly can out-compete the grazing animals. It is therefore important to understand the optimal growth conditions for this species (Hwang et al. 2007). The growth at each cultivation stage of S. fulvellum is controlled by managing the depth of the cultivation rope to maintain the optimal irradiance for growth.

Recently developed cultivation species. In Korea, an Ulva complex of mixed $U$. prolifera, $U$. compressa, $U$. intestinalis, E. linza, U. clathrata (Fig. 3E), Capsosiphon fulvescens (Fig. 3F), and Codium fragile (Fig. 3G) is also cultivated but production levels are currently very low. In 2017, the cultured production of Ulva complex, C. fulvescens and C. fragile was 6,159, 6,276, and 3,980 tonsfresh wt., respectively (Table 2). The production of Ulva spp. was 6,159 tons-fresh wt. (Table 1). Although there is a commercial demand for these species and there have been significant efforts to harvest it on an industrial scale, there are few places in Korea where U. prolifera production in the wild is sufficient to allow for commercial exploitation. This has led to the investigation of the opportunity for increasing production through stock enhancement (Yoon et al. 2003). As part of an investigation into increasing the yield of $U$. prolifera harvested from mudflats, Park and Hwang (2011) reported that the spa- 

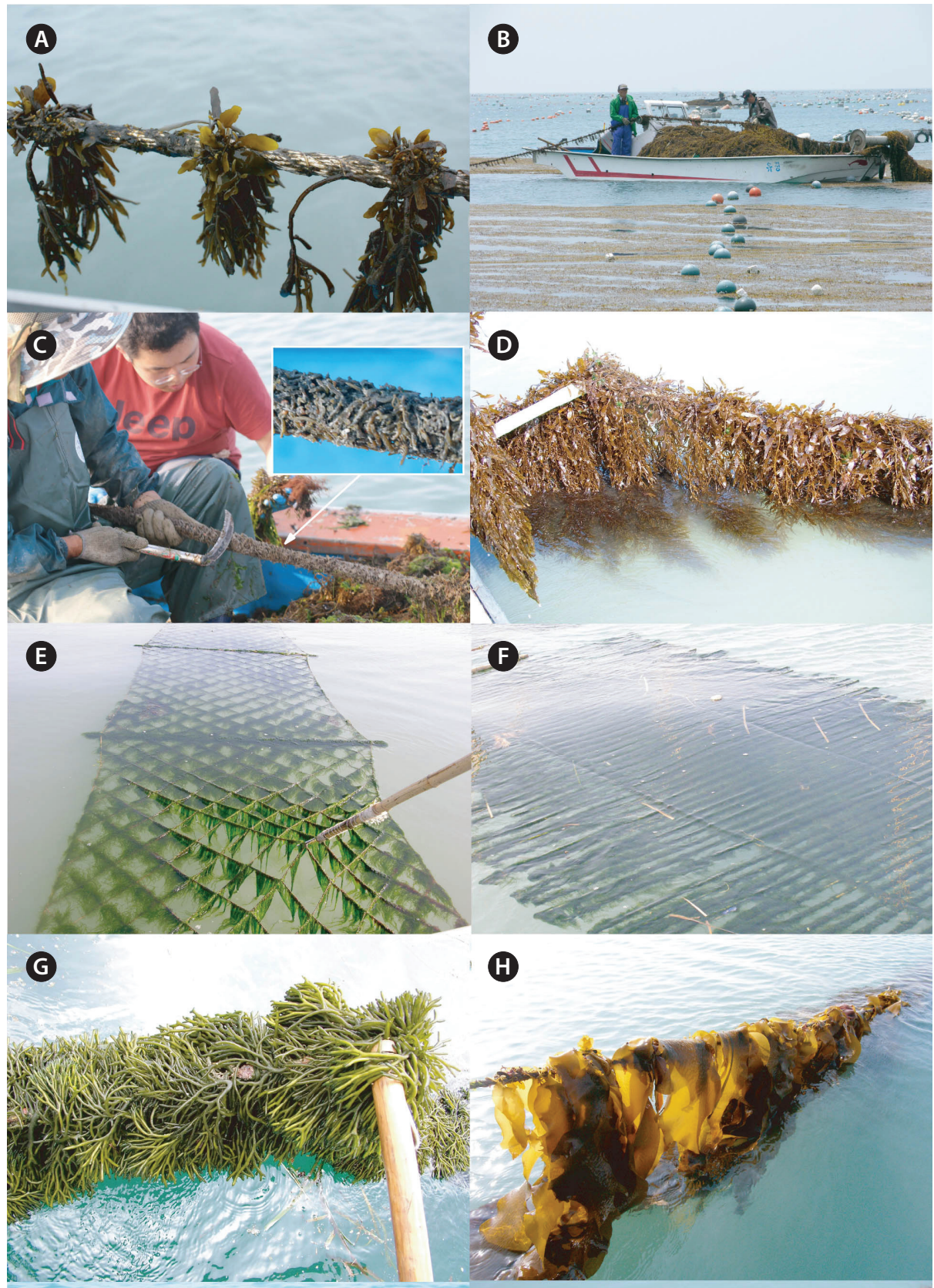

$\boldsymbol{\Theta}$

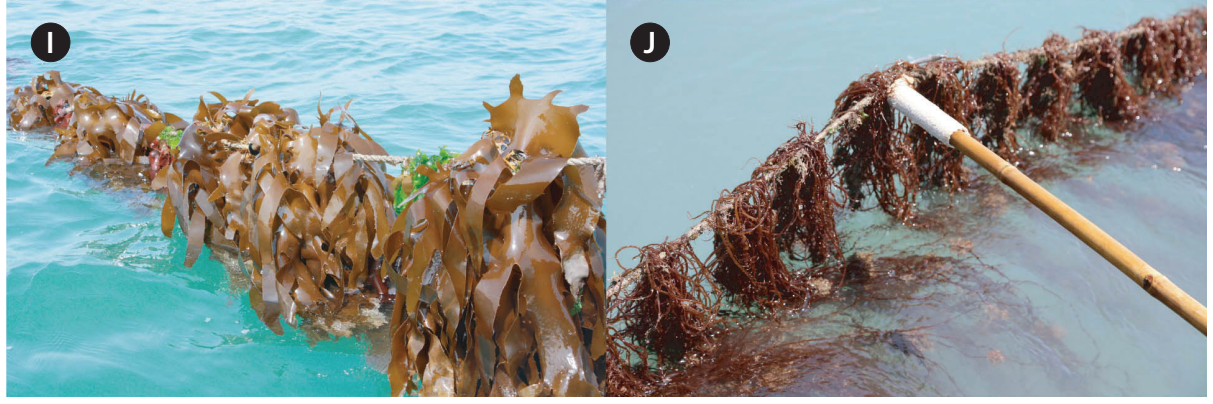

Fig. 3. Cultivation of Sargassum, Ulva, Capsosiphon, Codium, Ecklonia, and Gracilariopsis in Korea. (A) Insertion of young fronds of Sargassum fusiforme. (B) Harvest of S. fusiforme. (C) After harvesting, holdfast of S. fusiforme remained on the culture rope without any epiphytes. (D) Cultivation rope of S. fulvellum. (E) Cultivation net of Ulva spp. (F) Cultivation net of Capsosiphon fulvescens. (G) Cultivation rope of Codium fragile. (H) Cultivation rope of Ecklonia stolonifera. (I) Cultivation rope of E. cava. (J) Cultivation rope of Gracilaiopsis chorda. 
tial differences in abundance observed in the field were related to the ratio of sand to silt on the Muan mudflats, South Korea. The study has demonstrated that attachment and survival of zoospores of $U$. prolifera is dependent on particle size. By analyzing the quality of sediment in the intertidal flats, it should therefore be possible to estimate the potential for successful stock enhancement of this species with in a given estuary.

With its unique flavor and soft texture, C. fulvescens is traditionally used for soup in Korea (Sohn 1998). Largescale cultivation of this alga has succeeded both in laboratory and field experiments (Hwang et al. 2003). Currently, large-scale farming occurs out around Wando, on the southwestern coast of Korea. Hwang et al. (2008a) reported that the alga has the potential to be further exploited as human food and as an ingredient in formulated food. C. fragile is often produced by the settlement of wild zygotes onto culture lines. However, Hwang et al. (2008b) reported that using the regeneration capability of this alga could be a more reliable method for producing seed stock and have published methods for the artificial seed production and nursery culture for this species. The use of these medullary filament seeding methods increased production from less than $1 \mathrm{~kg}$-fresh wt. to ca. 7 kg-fresh wt. per $1 \mathrm{~m}$ culture rope. Ecklonia spp. are also cultivated in Korea. However, production levels are very low and consequently are not recorded in the national statistics. E. stolonifera (Fig. 3H) is used as food, feed, and seedlings for sea forest construction. E. cava (Fig. 3I) is also used as seedlings for the restoration of sea forest. The increasing demand for fresh algae from the abalone industry has provided the opportunity to investigate the culture of these species further. These algae are perennial and continue to grow and produce valuable biomass for abalone feed during the summer when other species of brown seaweed are not abundant (Hwang et al. 2013). Gracilariopsis chorda is cultured as human food and is mainly eaten in a steamed salad. Asexual propagation (regeneration) and spore seeding methods have been tried for the cultivation of this species (Sohn 2009), and 1,634 tons-fresh wt. were produced in 2017 (Table 1, Fig. $3 \mathrm{~J})$.

\section{Processing industry}

Traditionally Korean people used seaweeds in their raw or sun-dried forms for food. Since the 1980s many different seaweed food products have been developed, e.g., machine-dried Pyropia (Fig. 4A), toasted Pyropia, seasoning Saccharina jam, salted or cut Undaria, sun- dried Undaria (Fig. 4B) and S. fusiforme (Fig. 4C), etc. Recently several processed fast foods and various packaged goods (seaweed soup, seaweed powders for rice, seaweed noodles, etc.) also have been manufactured. Almost all harvested Pyropia is machine processed to form dried sheets. The number of similar seaweed processing companies rapidly increased during the 2010s, and the production of dried Pyropia amounted to ca. 200 million sheets $(21 \mathrm{~cm} \times 19 \mathrm{~cm}, 2.5 \mathrm{~g}$-dry wt.) in 2017. Thus the export of Pyropia is now the second most valuable marine product exported from Korea, with a value of approximately US\$ 525 million in 2017.

Salted Undaria was one of the most important processed seaweed products in Korea between the 1970s and 1990s and was manufactured mainly on the southwest coast of Korea. A decrease in the export of salted Undaria to Japan has led to a change in production from salted to dried Undaria. Dried Undaria has become a common product in Korea and is included in many processed foods, snacks, and well-being products that utilize the nutritional properties of Undaria.

Boiled and sun-dried S. fusiforme is also a commercially important product for export to Japan. Sun-dried S. fusiforme is used as a raw material for secondary products such as seasoning. Some of the pigments of $S$. fusiforme are lost during the heat treatment for secondary products, and the fronds are dyed to maintain their appearance using pigments extracted from Ecklonia cava (Sohn 1998). S. japonica is mainly sold as chopped dried products. Auctions (Fig. 4D) of dried S. japonica are held in June and July in Wando, southwestern coast of Korea.

U. prolifera (Fig. 4E) is dried in the form of sheets similar to Pyropia and has recently been processed into salt and oil (Fig. 4F). Various processed fast foods, snacks, and instant salads also have been manufactured from Ulva (Fig. 4G \& H). Seanol (sea polyphenol) is extracted from E. cava and has been commercialized for use in cosmetics, medical food, and treatment to manage human health and lifestyle (Fig. 4I). The extraction of agar-agar from Gelidium has historically been an important industry in Korea and has consistently been a leading export item. However, the agar processing industry has declined significantly (Sohn 1998) because most of the processing plants have moved offshore. At present, there are a few remaining agar processing plants and agar-agar exports account for only ca. US $\$ 3$ million in exports annually.

In addition to food uses, the market for health supplements such as tablets, extracts, jelly, and powder using kelp is expanding. Sales of beauty products (soaps, shampoos, body washes, bathing agents, etc.) using vari- 




Fig. 4. Seaweed processing and products of Korea. (A) Processing of Pyropia to dried sheets $(21 \mathrm{~cm} \times 19 \mathrm{~cm}$ in size, $2.5 \mathrm{~g}$-wet wt.). (B) Sun-dried Undaria pinnatifida. (C) Sun-dried Sargassum fusiforme. (D) Sun-dried Saccharina japonica waiting for the auction. (E) Sun-dried Ulva prolifera. (F) Fried with oil and salt of Pyropia. (G) Various products of Pyropia. (H) Snacks and instant salads of seaweeds. (I) Seaweed cosmetics. 
ous seaweeds are also increasing, and in some districts, local governments have created thallasiotherapy using seaweed. Seaweed uses also include medicines, food additives, livestock feeds, organic fertilizers, biodegradable materials, pulp, eco-friendly building materials, bio-energy sources, and materials for seaforest restoration.

With the increasing use of seaweed products, there have been calls for risk-benefit analyses to evaluate the health risks related to seaweed consumption (Barbier et al. 2019). Analysis including microbial and chemical risk assessment of seaweed products such as bacteria and heavy metals is necessary, and food safety must be secured during both aquaculture production and processing.

\section{BREEDING AND CULTIVARS}

In 2002, Korea joined the International Union for the Protection of New Varieties of Plants (UPOV) (Park et al. 2016, Hwang et al. 2019) and started to apply the varieties protection system to seaweed since 2012. To date, 19 seaweed cultivars have been registered, including $13 P y$ ropia, 5 Undaria, and 1 Saccharina (Table 4). These cultivars have contributed directly to industrial development and increased seaweed production significantly in Korea.

Pyropia spp. are the most important seaweeds in Korea, with 20 species and two subspecies recorded (Lee and Kang 1986, Hwang and Lee 2001, Kim and Kim 2011, Hwang et al. 2019). The goal of breeding Pyropia is to develop fast-growing, temperature-tolerant cultivars which are resistant to diseases and are also rich in highly desirable secondary metabolites (e.g., antioxidants, amino acids, vitamins, etc.). Three methods are used for Pyropia breeding; selection (Park and Hwang 2014), hybridization (Kim 2001), and mutation through mutagen induction (Lee and Choi 2018) or radiation treatment (Lee et al. 2019). Park and Hwang (2014) isolated the P. yezoensisAP1 variety, which was resistant to the pathogen, Pythium porphyrae that caused red rot disease in cultivation. Among 13 Pyropia cultivars registered for plant variety protection in Korea, 12 have been grown commercially. Also, 12 additional applications are being examined for registration (Hwang et al. 2019). Completion of the mitochondrial genome sequencing in $P$. yezoensis and $P$. retorta could provide novel molecular markers for systematic study, and may help differentiate cultivars (Hwang et al. 2014b, 2018b, Kim et al. 2018).

Undaria pinnatifida occurs throughout eastern Asia (Kang 1966) and is widely cultivated in Korea. The expanding abalone industry in Korea is closely associated with the seaweed aquaculture industry (Hwang et al. 2009), and Undaria is used as a fresh feed for abalone. However, the natural growth period of this species is not long enough to cover the period for which fresh seaweed

Table 4. List of registration seaweed cultivars in Korea (2012-2019)

\begin{tabular}{|c|c|c|c|c|c|}
\hline Genera & Species & Registration No. & Breeding method & Name of cultivar & Year \\
\hline \multirow[t]{13}{*}{ Pyropia } & P. yezoensis & APVP-1 & $\mathrm{S}$ & Pulmunoeul & 2014 \\
\hline & & APVP-6 & S & Haepoong No. 1 & 2015 \\
\hline & & APVP-7 & S & Pulmuhaesim & 2015 \\
\hline & & APVP-8 & S & Sugwawon No. 104 & 2015 \\
\hline & & APVP-11 & S & Sugwawon No. 105 & 2017 \\
\hline & & APVP-13 & M & Jeonsu No. 1 & 2017 \\
\hline & & APVP-15 & $\mathrm{S}$ & Sugwawon No. 108 & 2018 \\
\hline & & APVP-16 & $S$ & Haepoong No. 2 & 2019 \\
\hline & & APVP-17 & S & Sugwawon No. 106 & 2019 \\
\hline & & APVP-18 & S & Sugwawon No. 109 & 2019 \\
\hline & & APVP-19 & S & Sugwawon No. 110 & 2019 \\
\hline & P. seriata & APVP-12 & S & Haemodol No. 1 & 2017 \\
\hline & & APVP-14 & $\mathrm{S}$ & Shinpoong No. 1 & 2018 \\
\hline \multirow{5}{*}{ Undaria } & U. pinnatifida & APVP-2 & S & Sugwawon haeorum & 2014 \\
\hline & & APVP-3 & $S$ & Sugwawon bibari & 2014 \\
\hline & & APVP-4 & S & Sugwawon cheonghae & 2014 \\
\hline & & APVP-9 & $S$ & Sugwawon No. 201 & 2015 \\
\hline & & APVP-10 & $\mathrm{H}$ & Sugwawon No. 202 & 2016 \\
\hline Saccharina & S. japonica & APVP-5 & S & Jeongwan No. 1 & 2014 \\
\hline
\end{tabular}

Data from Aquatic Plant Variety Center, National Institute of Fisheries Science (2019) available from http://nifs.go.kr/apvc/index.ap.

$\mathrm{S}$, selected; $\mathrm{M}$, mutation; $\mathrm{H}$, hybrid. 
is required for feeding abalone. One goal of breeding $U n$ daria in Korea is therefore to develop high-temperature resistant varieties for supplying raw kelp feed, especially in the summer, so that the abalone growing season can be prolonged. Some success has been achieved by rearing hybrids of $U$. peterseniana (Kjellman) Okamura (male) and U. pinnatifida (female) to provide algal biomass for abalone when $U$. pinnatifida is not readily available (Hwang et al. 2011, 2012). This hybrid continued growing even after the growth of $U$. pinnatifida ceased in April (Hwang et al. 2014a). Trials showed that the hybrid not only provided an extended production period, it also provided greater biomass than U. pinnatifida. These hybrids are not currently fully utilized due to difficulties in mass-producing artificial seedings fr hybrids, but these issues are expected to be resolved in the near future. Among 5 Undaria cultivars that have been registered for plant variety protection, all were developed by selection or hybridization.

Driven by increasing demand for kelp feed from abalone farmers, the area used for farming $S$. japonica increased by $671 \%$ between 2001 to 2015, and the cultivation area is now 9,147 ha (Hwang et al. 2019). Technological advancements have supported the rapid development of the kelp farming industry for seedling-rearing and 'autumn sporeling-rearing' (Sohn 1998). Consecutive selection for three generations $\left(\mathrm{F}_{3}\right)$ in $S$. japonica targeted a cultivar with an extended cultivation period (Hwang et al. 2017). An application for registration of cultivar 'Sugwawon No. 301' has been made to the Korean government and once the registration process is completed, it will be distributed to seaweed growers. Hwang et al. $(2017,2018 a)$ demonstrated that cultivars displayed different morphological traits, temperature tolerance, and resistance to wave action when they grew in different environments. There is, therefore, the potential to increase productivity on seaweed farms by developing unique cultivars for specific environments. To date one Saccharina cultivar has been registered for variety protection in Korea.

\section{FUTURE PROSPECT OF SEAWEED CULTIVATION}

Korean seaweed cultivation has continued to grow since 1970s and Korea became the world's top exporter of Pyropia in 2017. This growth is the result of the development of seaweed cultivation technology which has focused on reducing labor and by pursuing the efficient use of technology, large-scale farming, development of automated harvesting and processing technologies, and increasing productivity through improved varieties and culture techniques. Looking to the future, seaweed cultivation will focus on deriving value from improved product quality and through more eco-friendly farming technologies rather than a single focus on increasing the quantity of seaweed produced. The recent and continued development of new high quality and disease-resistant varieties means that Korean seaweed cultivation has a bright future.

In addition to technological advances that lead to increased productivity from marine farms, there is a growing interest in indoor culture systems for seaweed. Development of indoor culture systems will help to secure the competitiveness of the industry and enable year-round production of seaweeds that compete with terrestrial vegetables. Locating such systems close to markets serves to meet consumer demand for fresh products while reducing the carbon emissions associated with transporting fresh materials from distant ports.

A changing climate will impact mariculture and reinforced the need to continue to develop varieties that can adapt to these new conditions. At the same time, consumer demands are changing, and the demand for functional foods and high-value seaweed extracts continues to rise. Research to support varieties that have a higher proportion of functional ingredients will increase the value of the industry without the need to increase production area or biomass. Techniques of seaweed breeding must also evolve to sustain the development of the seaweed farming industry, in response to an ever-changing environment. The Korean government has recognized the importance of seaweed breeding and has created the 'Golden Seed Project' supporting the development of seaweed cultivars to increase seaweed export earnings.

In a world where consumers are becoming increasingly aware of environmental sustainability as a key part of product quality, the industry must also meet the challenges of developing and demonstrating more ecofriendly practices. A seaweed company in Korea obtained the world's first ASC-MSC (Aquaculture Stewardship Council-Marine Stewardship Council) certification in 2019 and more are expected in the future as the Korean seaweed industry develops in line with the demands of eco-friendly and health-conscious consumers.

In summary, seven key challenges are facing that the Korean seaweed industry must meet to secure its growth:

1. Management and maintenance of the seaweed farming environment to maintain continuous productivity by understanding the environmental ca- 
pacity for production.

2. Raising awareness of environmental management with seaweed farmers and developing and promoting more environmentally sustainable practices.

3. Development of seaweed varieties that will allow the industry to adapt to the challenge of climate change.

4. Continuous development of value-added functional seaweed varieties that add value to the industry without the need to increase production area.

5. Development of new processed products and fresh convenience products to meet changes in consumer habits and facilitate the expansion of export markets.

6. Development of food safety protocols that meet international standards.

7. Administrative and financial support at the national level to secure the national and international status of the seaweed cultivation industry.

\section{ACKNOWLEDGEMENTS}

This research was supported by a grant from the National Institute of Fisheries Science, Republic of Korea (R2020008, P2020044). The authors would like to thank Dr. Philip Heath (Tisbe Ltd., New Zealand) for reviewing the English.

\section{REFERENCES}

Aquatic Plant Variety Center, National Institute of Fisheries Science. 2019. List of registration seaweed cultivars. Available from http://nifs.go.kr/apvc/index.ap. Accessed Aug 30, 2019.

Bae, S. H. 1991. The origin and development process of laver culture industry in Korea. 1. Laver culture history till the end of Chosun dynasty. Bull. Korean Fish. Soc. 24:153166.

Barbier, M., Charrier, B., Araujo, R., Holdt, S. L., Jacquemin, B. \& Rebours, C. 2019. Phycomorph European guidelines for a sustainable aquaculture of seaweeds. European Cooperation in Science and Technology, Nice, 194 pp.

Chang, J. W. \& Geon, S. H. 1970. Studies on the culture of Laminaria. (1) On the transplantation of tangle Laminaria religiosa Miyabe in temperate zone (the coast of Ilsan-Dong, Ulsan city). Bull. Fish. Res. Dev. Agency 5:63-75.

Choi, H. S., Choi, K. H. \& Rhew, T. H. 2000. Simple and rapid isolation of plasmids from Porphyra tenera. Algae
15:133-136.

Choi, S., Hwang, M. S., Im, S., Kim, N., Jeong, W. -J., Park, E. -J., Gong, Y. -G. \& Choi, D. -W. 2013. Transcriptome sequencing and comparative analysis of the gametophyte thalli of Pyropia tenera under normal and high temperature conditions. J. Appl. Phycol. 25:1237-1246.

Chung, M. K. 1937. Laver of Chosun. Fish. Chosun 144:1-4.

Food and Agriculture Organization of the United Nations. 2017. Fisheries and aquaculture statistics. Available from: http://www.fao.org/fishery/en. Accessed Aug 30, 2019.

Food and Agriculture Organization of the United Nations. 2018. The state of world fisheries and aquaculture 2018. Meeting the sustainable development goals. Food and Agriculture Organization of the United Nations, Rome, 227 pp.

Hong, Y. K., Sohn, C. H. \& Chang, J. W. 1989. Genetic improvement for the low salinity-tolerant Porphyra sp. by cell culture technique. I. Tissue culture of Porphyra yezoensis forma narawaensis. J. Aquac. 2:1-7.

Hwang, E. K., Amano, H. \& Park, C. S. 2008a. Assessment of the nutritional value of Capsosiphon fulvescens (Chlorophyta): developing a new species of marine macroalgae for cultivation in Korea. J. Appl. Phycol. 20:147-151.

Hwang, E. K., Baek, J. M. \& Park, C. S. 2007. Assessment of optimal depth and photo irradiance for cultivation of the brown alga, Sargassum fulvellum (Turner) C. Agardh. J. Appl. Phycol. 19:787-793.

Hwang, E. K., Baek, J. M. \& Park, C. S. 2008b. Cultivation of the green alga, Codium fragile (Suringar) Hariot, by artificial seed production in Korea. J. Appl. Phycol. 20:469475.

Hwang, E. K., Baek, J. M. \& Park, C. S. 2009. The mass cultivation of Ecklonia stolonifera Okamura as a summer feed for the abalone industry in Korea. J. Appl. Phycol. 21:585-590.

Hwang, E. K., Cho, Y. C. \& Sohn, C. H. 1999. Reuse of holdfasts in Hizikia cultivation. J. Korean Fish. Soc. 32:112-116.

Hwang, E. K., Gong, Y. G., Hwang, I. -K., Park, E. -J. \& Park, C. S. 2013. Cultivation of the two perennial brown algae Ecklonia cava and E. stolonifera for abalone feeds in Korea. J. Appl. Phycol. 25:825-829.

Hwang, E. K., Gong, Y. G. \& Park, C. S. 2011. Cultivation of a brown alga, Undariopsis peterseniana (Kjellman) Miyabe and Okamura, as a warm-temperature species by artificial seed production in Korea. J. Appl. Phycol. 23:449-455.

Hwang, E. K., Gong, Y. G. \& Park, C. S. 2012. Cultivation of a hybrid of free-living gametophytes between Undariopsis peterseniana and Undaria pinnatifida: morpho- 
logical aspects and cultivation period. J. Appl. Phycol. 24:401-408.

Hwang, E. K., Ha, D. S. \& Park, C. S. 2017. Strain selection and initiation timing influence the cultivation period of Saccharina japonica and their impact on the abalone feed industry in Korea. J. Appl. Phycol. 29:2297-2305.

Hwang, E. K., Hwang, I. K., Park, E. J., Gong, Y. G. \& Park, C. S. 2014a. Development and cultivation of $\mathrm{F}_{2}$ hybrid between Undariopsis peterseniana and Undaria pinnatifida for abalone feed and commercial mariculture in Korea. J. Appl. Phycol. 26:747-752.

Hwang, E. K., Kim, C. H. \& Sohn, C. H. 1994a. Callus-like formation and differentiation in Hizikia fusiformis (Harvey) Okamura. Korean J. Phycol. 9:77-83.

Hwang, E. K., Liu, F., Lee, K. H., Ha, D. S. \& Park, C. S. $2018 a$. Comparison of the cultivation performance between Korean (Sugwawon No. 301) and Chinese strains (Huangguan No. 1) of kelp Saccharina japonica in an aquaculture farm in Korea. Algae 33:101-108.

Hwang, E. K., Park, C. S. \& Sohn, C. H. 1994b. Effects of light intensity and temperature on regeneration, differentiation and receptacle formation of Hizikia fusiformis (Harvey) Okamura. Korean J. Phycol. 9:85-93.

Hwang, E. K., Yi, Y. H., Shin, W. J. \& Sohn, C. H. 2003. Growth and maturation of a green alga, Capsosiphone fulvescens, as a new candidate for seaweed cultivation in Korea. In Champman, R. O., Anderson, R. J., Vreeland, V. J. \& Davison, I. R. (Eds.) Seventeenth Int. Seaweed Symp., Oxford University Press, Oxford, pp. 59-64.

Hwang, E. K., Yotsukura, N., Pang, S. J., Su, L. \& Shan, T. F. 2019. Seaweed breeding programs and progress in eastern Asian countries. Phycologia 58:484-495.

Hwang, I. K., Kim, S. -O., Hwang, M. S., Park, E. -J., Ha, D. -S. \& Lee, S. -R. 2018b. Intraspecific variation of gene structure in the mitochondrial large subunit ribosomal RNA and cytochrome c oxidase subunit 1 of Pyropia yezoensis (Bangiales, Rhodophyta). Algae 33:49-54.

Hwang, M. S., Kim, S. -M., Ha, D. -S., Baek, J. M., Kim, H. -S. \& Choi, H. -G. 2005. DNA sequences and identification of Porphyra cultivated by natural seeding on the southwest coast of Korea. Algae 20:183-196.

Hwang, M. S., Kim, S. -O., Ha, D. -S., Lee, J. E. \& Lee, S. -R. $2014 \mathrm{~b}$. Complete mitochondrial genome sequence of Pyropia yezoensis (Bangiales, Rhodophyta) from Korea. Plant Biotechnol. Rep. 8:221-227.

Hwang, M. S., Kim, S. -O., Lee, Y. -S., Park, E. -J., Kim, S. -C., Ha, D. -S., Gong, Y. G., Baek, J. -M. \& Choi, H. -G. 2010. Isolation and characterization of pure lines of pigmentation and morphological mutants in Porphyra tenera Kjellman (Bangiales, Rhodophyta). Korean J. Fish.
Aquat. Sci. 43:495-502.

Hwang, M. S. \& Lee, I. K. 2001. Taxonomy of the genus Porphyra (Bangiales, Rhodophyta) from Korea. Algae 16:233-273.

Jin, L. -G., Kim, M. -S., Choi, J. -S., Cho, J. -Y., Jin, H. -J. \& Hong, Y. -K. 2000. Morphology and sequence analysis of nuclear 18S rDNA from the summer strain of Porphyra suborbiculata (Rhodophyta) in Korea. J. Korean Fish. Soc. 33:489-495.

Kang, J. W. 1966. On the geographical distribution of marine algae in Korea. Bull. Pusan Fish. Coll. 7:1-136.

Kang, J. W. 1972. Species of cultivated Porphyra in Korea. In Nisizawa, K. (Ed.) Proc. 7th Int. Seaweed Symp. Univ., Tokyo Press, Tokyo, pp. 108-110.

Kang, J. W. \& Koh, N. P. 1977. Algal mariculture. Taehwa Publ. Co., Busan, Korea, 294 pp.

Kim, E., Park, H. -S., Jung, Y., Choi, D. -W., Jeong, W. -J., Park, H. -S., Hwang, M. S., Park, E. -J. \& Gong, Y. G. 2011. Identification of the high-temperature response genes from Porphyra seriata (Rhodophyta) expression sequence tags and enhancement of heat tolerance of Chlamydomonas (Chlorophyta) by expression of the Porphyra HTR2 gene. J. Phycol. 47:821-828.

Kim, H. -S. \& Kim, S. -M. 2011. Algal flora of Korea. Vol. 4, No. 1. Primitive red algae. National Institute of Biological Resources, Incheon, 138 pp.

Kim, N. G. 2001. Physiological study on the hybrid by interspecific crossing between Porphyra pseudolinearis and P. dentata (Bangiales, Rhodophyta), two dioecious species in culture. J. Aquac. 13:353-357.

Kim, S. -M., Choi, H. -G., Hwang, M. -S. \& Kim, H. -S. 2018. Biogeographic pattern of four endemic Pyropia from the east coast of Korea, including a new species, Pyropia retorta (Bangiaceae, Rhodophyta). Algae 33:55-68.

Korea Customs Service. 2019. Customs statistics. Available from: http://www.customs.go.kr. Accessed Mar 30, 2020.

Lee, H. -J. \& Choi, J. -I. 2018. Isolation and characterization of a high-growth-rate strain in Pyropia yezoensis induced by ethyl methane sulfonate. J. Appl. Phycol. 30:2513-2522.

Lee, H. -J., Park, E. -J. \& Choi, J. -I. 2019. Isolation, morphological characteristics and proteomic profile analysis of thermo-tolerant Pyropia yezoensis mutant in response to high-temperature stress. Ocean Sci. J. 54:65-78.

Lee, I. -K. \& Kang, J. W. 1986. A check list of marine algae in Korea. Korean J. Phycol. 1:311-325.

Ministry of Oceans and Fisheries. 2018. Fisheries statistics. Available from: https://portal.fips.go.kr. Accessed Aug 30, 2019. 
Oohusa, T. 1993. The cultivation of Porphyra "Nori”. In Ohno, M. \& Chritchley, A. T. (Eds.) Seaweed Cultivation and Marine Ranching. Japan International Cooperation Agency (JICA), Yokosuka, pp. 57-74.

Park, C. S. \& Hwang, E. K. 2011. An investigation of the relationship between sediment particles size and the development of green algal mats (Ulva prolifera) on the intertidal flats of Muan, Korea. J. Appl. Phycol. 23:515-522.

Park, C. S. \& Hwang, E. K. 2014. Isolation and evaluation of a strain of Pyropia yezoensis (Bangiales, Rhodophyta) resistant to red rot disease. J. Appl. Phycol. 26:811-817.

Park, C. S. \& Hwang, E. K. 2015. Biochemical characterization of Pyropia yezoensis-AP1 strain accompanies the resistance reaction to the red rot disease pathogen, $P y$ thium porphyrae. J. Appl. Phycol. 27:2149-2156.

Park, C. -W., Choi, K. -J., Soh, E. -H. \& Koh, H. -J. 2016. Study on the future development direction of plant variety protection system in Korea. Korean J. Breed. Sci. 48:1121.

Shin, J. -A. 2003. Quality improvement of dried sheets of Porphyra using recombinant wild-type in P. yezoensis (Bangiales, Rhodophyta). Algae 18:95-100.

Shin, J. -A., Miura, A. \& Fu, P. F. 1997. Hybrid breakdown and breakthrough in interspecific crosses between Porphyra yezoensis and P. tenera. National History Research, Special Issue 3:65-70.

Sohn, C. -H. 1996. Historical review on seaweed cultivation of Korea. Algae 11:357-364.

Sohn, C. H. 1998. The seaweed resources of Korea. In Critchley, A. T. \& Masao, O. (Eds.) Seaweed Resources of the World. Japan International Cooperation Agency, Yokosuka, pp. 15-33.

Sohn, C. H. 2009. Seaweed cultivation. Dain Communications, Busan, 283 pp.

Sohn, C. H. \& Kain, J. M. 1989. Porphyra cultivation in Korea. In Kain (Jones), J. M., Andrews, J. W. \& MacGregor, B. J. (Eds.) Outdoor Seaweed Cultivation. Proc. 2nd Workshop of COST 48 Subgroup 1, Port Erin, pp. 106-109.

Yoo, J. G. 1964. Experiment of PVA net in Porphyra cultivation. Technical Report of National Fisheries Research \& Development Agency. National Fisheries Research and Development Agency of Korea, Busan, 36 pp.

Yoon, J. T., Cho, Y. C. \& Gong, Y. G. 2003. A study on the cultivation of Enteromorpha prolifera (Müller) J. Agardh, Chlorophyta in Korea. J. Aquac. 16:44-50. 